\title{
Surgical Excision of An Epulis: Case Report
}

\section{Besas P, Chatzopoulou D, Ryan P and Gillam DG*}

Queen Mary University London, London

Submission: August 15, 2018 Published: September 12, 2018

*Corresponding author: Gillam DG, Oral Bio Engineering, Institute of Dentistry, Barts and the London School of Medicine and Dentistry, Queen Mary University London, London E1 2AD, Email: d.g.gillam@qmul.ac.uk

\begin{abstract}
Introduction: Any localised swelling of the gingivae may be called an epulis although its usage is normally restricted to developmental or reactive swellings of the gingivae or periodontal ligament origin. The swelling is usually a result of a local irritant such as calculus formation or a poorly adapted margin of a dental restoration. A rather special type of epulis is the so called epulis gravidarum or pregnancy tumour. These swellings tend to regress after parturition although in some situations the adjacent teeth may be affected by the enlargement of the gingival tissues and start to drift.
\end{abstract}

Aim: The aim of this case report is to describe a surgical technique for the removal of an epulis, which was located at the aesthetic zone of the lower incisors, and to report on associated changes in the periodontal parameters such gingival inflammation and the position of the tooth following the introduction of an effective oral hygiene regime for the patient.

Conclusion: The maintenance of the patient's postsurgical gingival health and the resultant aesthetic appearance following realignment of the displaced incisor tooth were related to

1. the surgical technique used and

2. the patient's compliance in maintaining optimum plaque control.

The maintenance of an optimal level of oral hygiene is therefore essential in the preservation of the gingival health following the surgical removal of an epulis. Furthermore, an additional benefit following the surgical removal of the gingival overgrowth was the improvement of the tooth position in the dental arch.

Keywords: Epulis; Epulis gravidarum; Pregnancy tumour; Surgical intervention

\section{Introduction}

Any localised swelling of the gingivae may be called an epulis although its usage is normally restricted to developmental or reactive swellings of the gingivae or periodontal ligament origin. The swelling is usually a result of a local irritant such as calculus formation or a poorly adapted margin of a dental restoration. A rather special type of epulis is the so called epulis gravidarum or pregnancy tumour. It has been suggested that progesterone levels in the gingival tissues of pregnant women with poor oral hygiene may allow an increased chronic-type of tissue reaction, resulting clinically in an exaggerated appearance of gingival inflammation. According to Pirie et al. [1] the prevalence of this epulides is up to $5 \%$ of pregnancies and is common in the early stage of pregnancy and may cause the adjacent teeth to drift. It may however be prudent for the clinician to wait until parturition before intervening and removing the lesion since these lesions tend to regress in size after the birth of the child. However, in some cases where the lesion is interfering with chewing or affecting the adjacent teeth then the clinician may undertake surgical intervention under local anaesthesia using conventional surgical techniques or the use of lasers to minimise post-operative bleeding [2].
Aim

The aim of this case report is to describe a surgical technique for the removal of an epulis, which was located at the aesthetic zone of the lower incisors, and to report on associated changes in the periodontal parameters such gingival inflammation and the position of the tooth following the introduction of an effective oral hygiene regime for the patient.

\section{Materials and Methods}

\section{Description}
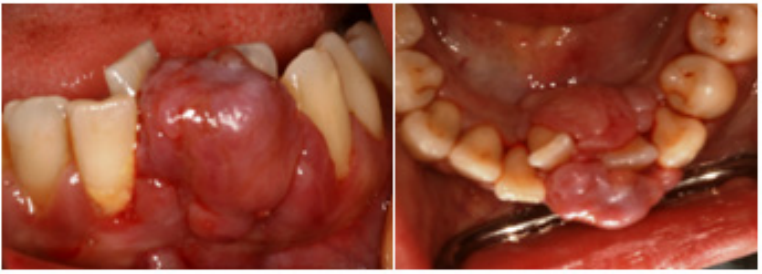

Figure 1: Initial clinical situation. 
A 22-year-old pregnant, female with no relevant medical history presented in the postgraduate periodontal clinic at the Dental Hospital with a gingival overgrowth on the labial and lingual aspects of the lower left mandibular incisors (Figure 1).

Following the initial examination, the patient received one course of non-surgical periodontal treatment and after the completion of this initial phase of treatment, the overgrowth was removed surgically under local anaesthesia as follows:

1. Intracrevicular incisions were performed both labially and lingually from the distal aspect of LL2 to the mesial aspect of LL1. A further horizontal incision was performed at the base of the overgrowth on each side and the lesion was removed.

2. An electrosurgical kit was used to control the excessive bleeding.

3. Full thickness flaps were raised, and the teeth were meticulously cleaned.

4. Interrupted sutures were secured covering both the lingual and labial flaps.

5. The patient was provided with post-operative instructions, including oral hygiene instruction to maintain the surgical area using a $0.2 \%$ Chlorhexidine digluconate mouth rinse (Corsodyl, GSK, UK) and asked to return for the removal of the sutures (Figure 2).

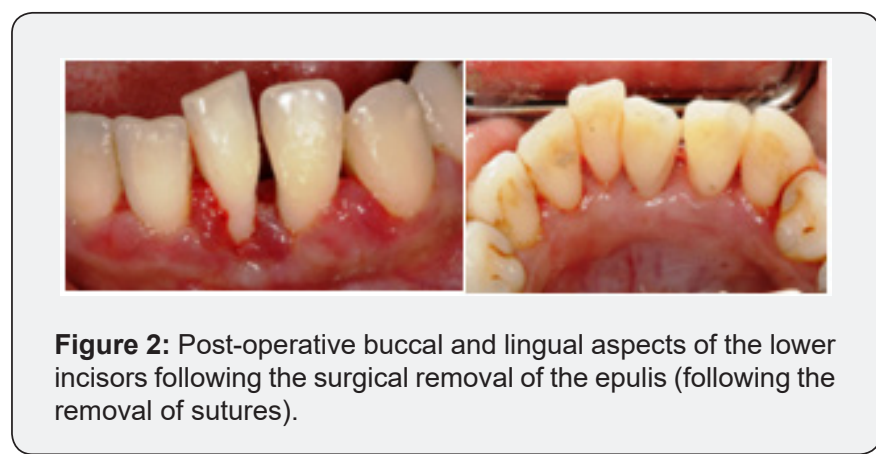

\section{Discussion}

As indicated by Robinson et al. [2] it may be prudent for the clinician to wait until parturition before intervening and removing the lesion since these lesions tend to regress in size after the birth of the child. However, in the situation described in the case study it was evident that the patient was in discomfort when chewing her food and the adjacent teeth were displaced by the enlarged size of the lesion and a decision was therefore made to intervene surgically. The surgery to remove the epulis was successful, although initially the poor compliance in maintaining good oral hygiene impeded the healing of the gingival tissues as evidence at the three-month visit (Figure 3). However, at the five months visit the patient's compliance had improved and there was resolution of the gingival inflammation around the lower teeth (Figure 4). It was evident that following the surgical removal of the epulis and subsequent non-surgical debridement of the lower incisors there was an overall improvement in the gingival condition. An interesting outcome following surgical invention was the repositioning of the previously misaligned central incisor to its pre-epulis position as observed in Figure 5. It is essential following surgical intervention that the importance of maintaining meticulous care of the oral tissues at home is emphasised to the patient by the clinician as well as follow up appointments to monitor the periodontal condition of the patient.
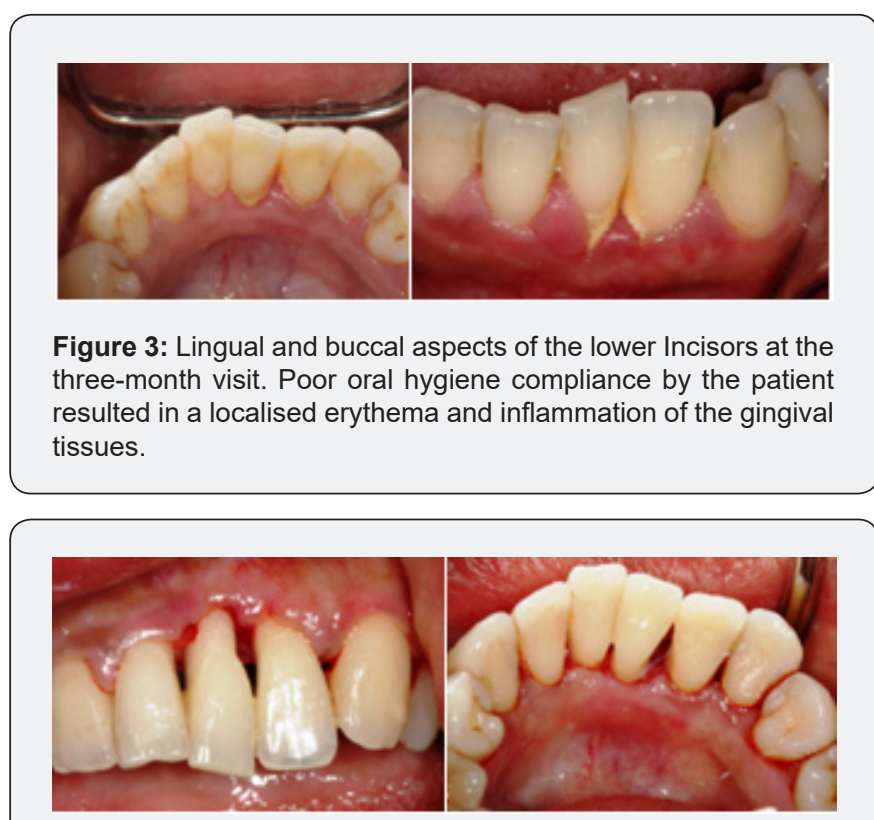

Figure 4: Buccal and lingual views of the lower incisors at 5 months.

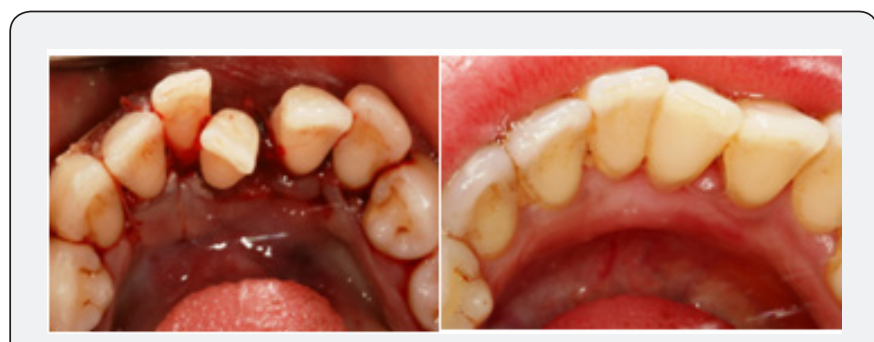

Figure 5: Comparison of the position of the lower mandibular incisors following surgery and at five months.

\section{Conclusion}

In conclusion, the maintenance of the patient's post-surgical gingival health and the resultant aesthetic appearance following realignment of the displaced incisor tooth were related to:

1. The surgical technique used and

2. The patient's compliance in maintaining optimum plaque control.

The maintenance of an optimal level of oral hygiene is therefore essential in the preservation of the gingival health following the surgical removal of an epulis. Furthermore, an additional benefit following the surgical removal of the gingival overgrowth was the improvement of the tooth position in the dental arch. 


\section{References}

1. Pirie M, Cooke I, Linden G, Irwin C (2007) Dental manifestations of pregnancy. The Obstetrician \& Gynaecologist 9(1): 21-26.
2. Robinson PJ, Maddalozzo D (2015) Influence of Pregnancy on the oral cavity. M Glob libr women's med.

\section{Your next submission with Juniper Publishers will reach you the below assets}

- Quality Editorial service

- Swift Peer Review

- Reprints availability

- E-prints Service

- Manuscript Podcast for convenient understanding

- Global attainment for your research

- Manuscript accessibility in different formats

( Pdf, E-pub, Full Text, Audio)

- Unceasing customer service

Track the below URL for one-step submission https://juniperpublishers.com/online-submission.php 